\title{
Fatigue among working people: validity of a questionnaire measure
}

Anna J H M Beurskens, Ute Bültmann, IJmert Kant, Jan H M M Vercoulen, Gijs Bleijenberg, Gerard M H Swaen

\begin{abstract}
Objectives-To evaluate the validity of the checklist individual strength questionnaire (CIS) in the working population. This 20 item self reported questionnaire has often been used in patients with chronic fatigue. To date, no research has focused on the validity of the CIS in occupational groups.

Methods-To evaluate the discriminant validity the CIS was filled out by five groups of employees with expected differences in fatigue. The convergent validity was evaluated by comparing the results of the CIS with the results of three related measures: measured unidimensional fatigue, burnout, and need for recovery. Results-The CIS was able to discriminate between fatigued and non-fatigued employees in occupational groups. The expected agreement between the results of the CIS and related measures was confirmed.

Conclusions-The CIS seems to be an appropriate instrument for measuring fatigue in the working population.

(Occup Environ Med 2000;57:353-357)
\end{abstract}

Keywords: fatigue; occupational groups; measurement

Fatigue at work is a normal everyday experience. However, in the case of severe fatigue it may affect the person's performance in the occupational as well as the home setting. Moreover, severe long term fatigue may lead to sick leave and work disability.

In The Netherlands about one in every three

Department of

Epidemiology,

Maastricht University,

PO Box 616, 6200 MD

Maastricht, The

Netherlands

A J H M Beurskens

U Bültmann

IJ Kant

G M H Swaen

Department of

Medical Psychology,

University Hospital

Nijmegen, The

Netherlands

J H M M Vercoulen

G Bleijenberg

Correspondence to:

Dr A Beurskens

aihm.Beurskens@

epid.unimaas.nl

Accepted 30 December 1999 recipients of work disability benefit is classifie as occupationally disabled on mental grounds. ${ }^{1}$ They have an "exogenous reaction", ${ }^{2}$ which is the official diagnosis that includes chronic job stress and burnout - that is, a mental state closely related to mental fatigue.

In 1996 a large scale national concerted research action on fatigue at work was initiated in The Netherlands. This multidisciplinary research programme includes psychological and medical research and is supported by grants from The Netherlands Organisation for Scientific Research (NWO), universities, occupational health services, private research institutes, trade unions, and business. ${ }^{3}$

Within the research programme fatigue is defined as:

"The change in the psychological control mechanism that regulates task behaviour, resulting from preliminary mental and/or physical efforts which have become bother- some to such an extent that the individual is no longer able to adequately meet the demands that the job requires on his or her mental functioning, or that the individual is able to meet these demands only at the cost of increasing mental effort and the surmounting of psychic resistance". ${ }^{3}$

We see fatigue, in line with Lewis and Wessely, ${ }^{4}$ as a subjective sensation with emotional, behavioural, and cognitive components. There is an essential difference between acute fatigue and long term fatigue. Acute fatigue is characterised by reversibility, task specificity, and the functional use of compensation mechanisms. Acute fatigue is a normal phenomenon that disappears after a period of rest, when tasks are switched, or when particular strategies are used-for example, working at a slower pace. By contrast, long term fatigue is irreversible, not task specific, and the compensation mechanisms that were useful in reducing acute fatigue are no longer effective.

To gain more insight in the aetiology and prognosis of long term fatigue at work one of the research programmes within the national concerted research action studies is the epidemiology of long term fatigue. A large scale longitudinal prospective cohort study was started in May 1998. The cohort study surveys a heterogenous population of over 12000 employees from different companies and organisations. The follow up is 3 years. Data on work related, psychological, social, physical, and behavioural factors, as well as on the health outcomes fatigue, burnout, need for recovery, and sick leave were collected by means of self administered questionnaires and sick leave administrations systems.

Instruments available to assess fatigue can be divided into unidimensional instruments and multidimensional instruments. According to Smets et $a l^{6}$ the use of unidimensional instruments excludes the possibility of a more complete description of fatigue. The wording of a single question can introduce substantial difference $^{4}$ and may emphasise only one dimension of fatigue. Within the cohort study we have chosen a multidimensional assessment of fatigue.

The multidimensional checklist individual strength questionnaire (CIS $)^{7-11}$ was used to measure chronic fatigue (see appendix). The CIS was designed to measure several aspects of fatigue which is in line with our definition of fatigue. It consists of four dimensions: the subjective experience of fatigue and reduction in motivation, reduction in activity, and reduction in concentration. The CIS was 
Table 1 Characteristics of the employees

\begin{tabular}{lccccc}
\hline & $\begin{array}{l}\text { White } \\
\text { collar }\end{array}$ & Blue collar & $\begin{array}{l}\text { Somatic after } \\
\text { hernia }\end{array}$ & $\begin{array}{l}\text { Somatic } \\
\text { pregnant }\end{array}$ & Mental \\
\hline Age (mean (SD)) & $35(6.4)$ & $35.8(8.9)$ & $43(7.4)$ & $31(2.7)$ & $44(9.1)$ \\
Sex (\% female) & $51 \%$ & $3 \%$ & $37 \%$ & $100 \%$ & $46 \%$ \\
Supervisor (\% yes) & $24 \%$ & $16 \%$ & $32 \%$ & $23 \%$ & $14 \%$ \\
Education level` (median) & 7 & 2 & 3.5 & 6 & 6 \\
Sick leave (\%) & $0 \%$ & $0 \%$ & $100 \%$ & $13 \%$ & $68 \%$ \\
Hours work & 40 & 41 & 39 & 32 & 35 \\
\hline
\end{tabular}

${ }^{\star}$ Scored on a 7 point scale: lowest education is primary school (1), highest education is university (7)

tested thoroughly in the clinical setting among patients with chronic fatigue syndrome and other chronic diseases and healthy controls. ${ }^{7-11}$ The internal consistency of the CIS seemed to be good: Chronbach's $\alpha$ for the total CIS was 0.90 and for the scales the $\alpha$ ranged from 0.83 to $0.92 .^{11}$ The CIS was able to discriminate between patients with chronic fatigue syndrome, patients with multiple sclerosis, and healthy controls and the convergent validity was also satisfying. ${ }^{8}$

There is, however, no work to date that focuses on the validity of the CIS in the working population. For that reason, a validity study was conducted. The aim of this study was to evaluate the ability of the multidimensional CIS in classifying employees according to their level of fatigue. The CIS was filled out by five groups of employees with expected differences in fatigue: two groups of healthy employees, two groups of employees with a somatic reason for fatigue, and one group with a mental reason for fatigue. Also, the scores on the CIS in the working groups were compared with a reference group of patients with chronic fatigue syndrome. Our hypotheses were that the employees with a mental reason for fatigue and the employees with a somatic reason for fatigue would score higher on all dimensions of the CIS than the healthy employees. The convergent validity of the CIS was evaluated by comparing the results of the CIS with the results of three related measures: fatigue measured on a unidimensional five point Likert scale, burnout, and need for recovery.

Burnout is a mental state which can be regarded as an extreme expression of long term fatigue. ${ }^{12}$ The employees' need for recovery ${ }^{13}$ can be considered as a mediating or moderating characteristic in the aetiology of fatigue.

\section{Subjects and methods}

STUDY POPULATION

To evaluate the ability of the CIS to discriminate between fatigued and non-fatigued subjects we formed five sets of employees with expected differences in fatigue: two sets of healthy employees, two sets of employees with a somatic reason for fatigue, and one set with a mental reason for fatigue. All employees were employed for $\geqslant 20$ hours a week.

The first group of employees consisted of 37 healthy white collar workers with mental work, mostly working at a university. The second group consisted of 38 healthy blue collar workers with industrial work. These employees performed heavy, dirty work in an iron foundry. We asked the healthy employees to fill out the questionnaire. The third group compared 38 patients who had had an operation for low back pain hernia. The physiotherapists in attendance asked the patients to fill out the questionnaire 5-7 days after the operation. The fourth group of employees were pregnant women $(n=47)$. The median duration of the pregnancy was 27 weeks. Their midwives asked if they wanted to participate in the study. The third and fourth groups had a somatic reason for fatigue. Company doctors and insurance doctors selected the fifth group with a mental reason for fatigue. We asked the doctors to select employees with a mental reason for fatigue and to exclude employees with psychiatric illness. The doctors asked eligible patients to fill out the questionnaire. In total, 59 employees with a mental reason for fatigue returned the questionnaire. For privacy reasons we do not know the exact diagnosis of these subjects.

Table 1 shows the characteristics of the five groups of employees. The groups were different on some characteristics but most differences were related to the selection of the groups - for example, sex in the group of pregnant women. However, the education level in the fifth group was high. This can be explained by the fact that the employees in this group were mainly white collar workers.

\section{QUESTIONNAIRE}

All 219 employees received a self administered questionnaire which contained questions about demographic factors, fatigue, burnout, need for recovery, and sick leave.

The CIS was used to measure fatigue, it consists of 20 statements for which the person has to indicate on a 7 point scale to what extent the particular statement applies to him or her. ${ }^{7}$ The statements refer to aspects of fatigue experienced during the previous 2 weeks. The number of items per dimension varies. The dimension "subjective fatigue" has eight items - for example, I feel tired-"reduction in motivation" four items-for example, I feel no desire to do anything - "reduction in activity three items-for example, I don't do much during the day-and reduction in concentration five items - for example, My thoughts easily wander. Also, by adding the four dimensions a CIS total score can be calculated. Higher

Table 2 Scores on the dimensions of the CIS (means (SD)) in the groups of employees and p values for the differences with the mental group (Bonferroni correction)

\begin{tabular}{|c|c|c|c|c|c|c|c|c|c|}
\hline & $\begin{array}{l}\text { White collar } \\
(n=37)\end{array}$ & $p$ Value & $\begin{array}{l}\text { Blue collar } \\
(n=38)\end{array}$ & $p$ Value & $\begin{array}{l}\text { After hernia } \\
(n=38)\end{array}$ & $p$ Value & $\begin{array}{l}\text { Pregnant } \\
(n=47)\end{array}$ & $p$ Value & $\begin{array}{c}\text { Mental } \\
(n=59)\end{array}$ \\
\hline Subjective fatigue (8 items) & $20.3(10.1)$ & 0.00 & $21.9(11.4)$ & 0.00 & $32.9(11.7)$ & 0.07 & $33.9(13.0)$ & 0.14 & $39.6(12.1)$ \\
\hline Activity ( 3 items) & $6.0(2.7)$ & 0.00 & $5.6(3.0)$ & 0.00 & $9.4(5.2)$ & 0.26 & $8.9(5.0)$ & 0.04 & $11.6(5.7)$ \\
\hline Motivation (4 items) & $9.3(4.8)$ & 0.00 & $9.9(5.1)$ & 0.00 & $11.2(5.5)$ & 0.00 & $13.3(6.0)$ & 0.00 & $17.8(6.6)$ \\
\hline Concentration (5 items) & $12.0(5.0)$ & 0.00 & $9.9(5.4)$ & 0.00 & $14.4(5.8)$ & 0.00 & $14.6(6.8)$ & 0.00 & $20.7(8.3)$ \\
\hline CIS total (20 items) & $47.3(19.8)$ & 0.00 & $47.3(18.9)$ & 0.00 & $67.7(23.5)$ & 0.00 & $70.7(24.9)$ & 0.00 & $89.7(26.2)$ \\
\hline
\end{tabular}




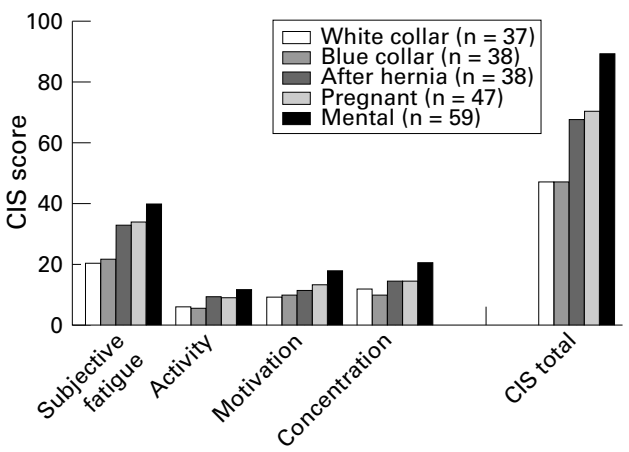

Figure 1 CIS scores in different groups of the working population.

scores indicate a higher degree of fatigue, more concentration problems, reduced motivation, and less activity.

Fatigue was also measured on a unidimensional five point Likert scale. Employees were asked to rate their perceived fatigue during the previous 2 weeks, ranging from "very often" to "rarely or never".

Burnout was measured with the Maslach burnout inventory - general survey (MBI-GS). The Maslach burnout inventory was originally developed to measure burnout in human service providers. ${ }^{12}$ Recently, a measure of burnout was developed which can be used also in other occupations the MBI-GS. ${ }^{12}$ This MBI-GS has three subscales that parallel the MBI: exhaustion, cynicism, and professional efficacy. The exhaustion items are generic, without the MBI's emphasis on emotions and without direct reference to service recipients. The items include references to both emotional and physical fatigue. The items of the subscale cynicism reflect indifference or a distant attitude toward work itself. A strong degree of exhaustion, cynicism, and a low degree of profession efficacy are indicative for the syndrome burnout. ${ }^{15}$

The need for recovery was measured with six items from a validated Dutch questionnaire about psychosocial job demands on job stress. ${ }^{13}$ The questions asked about the situation at the end of a working day-for example, if the employees still feel fresh after supper or if they are able to relax only on a second day off.

\section{ANALYSES}

All data analyses were done with SPSS statistical software. ${ }^{16}$ To gain insight in the discriminant validity, differences among the five groups of employees for the four dimensions of the CIS were calculated with univariate analyses of variance (ANOVA). Because we are especially interested in the differences between the healthy employees and the employees with a somatic reason for fatigue on the one hand and the mental group on the other, we evaluated whether these differences were significant with a Bonferroni correction ( $\alpha$ 0.05). One way analyses of covariance (ANCOVA) was used to adjust for differences in age, sex, and education of the employees.

To evaluate the convergent validity the differences among the five groups of employees for the three related measures was compared with the discriminant results of the CIS. We expected that the agreement between the dimensions of the CIS and the scale exhaustion of the MBI-GS would be better than with the scales cynicism and profession efficacy, because these scales measure other aspects of work. Also, to evaluate the relation between CIS total and the scale exhaustion of the MBI-GS in the group of employees with a mental reason for fatigue we made a scatterplot and calculated the Pearson correlation coefficient.

\section{Results}

DISCRIMINANT VALIDITY

Table 2 shows the mean (SD) of the groups of employees on the dimensions of the CIS. Figure 1 shows the distribution of the scores graphically. The employees with a mental reason for fatigue scored systematically higher on all dimensions of the CIS. Also, the employees with somatic reasons for fatigue had higher scores than the healthy employees. For the dimensions reduction in motivation and concentration, and for the total CIS the differences between the group with a mental reason for fatigue and all the other groups were significant.

The scores on the CIS in the working groups were compared with a reference group of 748 patients with the chronic fatigue syndrome from a study of Vercoulen et al. ${ }^{7}$ The mean scores of patients with chronic fatigue syndrome were for subjective fatigue 51.7 , reduction in activity 16.9 , reduction in motivation 17.0, reduction in concentration 27.5, and for CIS total $113.1 .^{7}$ These scores were substantially higher than the scores of healthy employees and employees with a somatic reason for fatigue. Except for the dimension reduction in motivation, these scores were also higher than the scores of the employees with a mental reason for fatigue.

Table 1 shows that the education level of the employees in the group with a mental reason for fatigue was high. We corrected for the effect of education, age, and sex with ANCOVA. However, the adjustments were not significantly different and only slightly changed the CIS scores.

Table 3 Scores on the dimensions of the MBI-GS, need for recovery and fatigue (mean (SD)) in the groups of employees and $p$ values for the differences with the mental group (Bonferroni correction)

\begin{tabular}{|c|c|c|c|c|c|c|c|c|c|}
\hline & $\begin{array}{l}\text { White collar } \\
(n=37)\end{array}$ & p Value & $\begin{array}{l}\text { Blue collar } \\
(n=38)\end{array}$ & p Value & $\begin{array}{l}\text { After hernia } \\
(n=38)\end{array}$ & p Value & $\begin{array}{l}\text { Pregnant } \\
(n=47)\end{array}$ & p Value & $\begin{array}{l}\text { Mental } \\
(n=59)\end{array}$ \\
\hline MBI-GS Exhaustion & $1.7(1.0)$ & 0.00 & $1.7(1.2)$ & 0.00 & $1.8(1.0)$ & 0.00 & $2.0(1.3)$ & 0.00 & $3.6(1.5)$ \\
\hline MBI-GS Cynicism & $1.4(0.9)$ & 0.00 & $1.7(1.2)$ & 0.18 & $1.8(1.1)$ & 0.18 & $1.5(1.1)$ & 0.00 & $2.3(1.3)$ \\
\hline MBI-GS Professional efficacy & $4.2(0.9)$ & 1.0 & $4.0(1.2)$ & 1.0 & $4.4(1.0)$ & 0.52 & $4.4(0.8)$ & 0.17 & $4.0(1.0)$ \\
\hline Fatigue, unidimensional & $2.6(0.7)$ & 0.00 & $2.4(1.1)$ & 0.00 & $3.1(1.0)$ & 0.02 & $3.6(1.0)$ & 1.0 & $3.8(1.0)$ \\
\hline Need for recovery & $0.28(0.28)$ & 0.00 & $0.44(0.30)$ & 0.00 & $0.34(0.31)$ & 0.00 & $0.42(0.33)$ & 0.00 & $0.77(0.27)$ \\
\hline
\end{tabular}

MBI-GS=Maslach burnout inventory—general survey. 


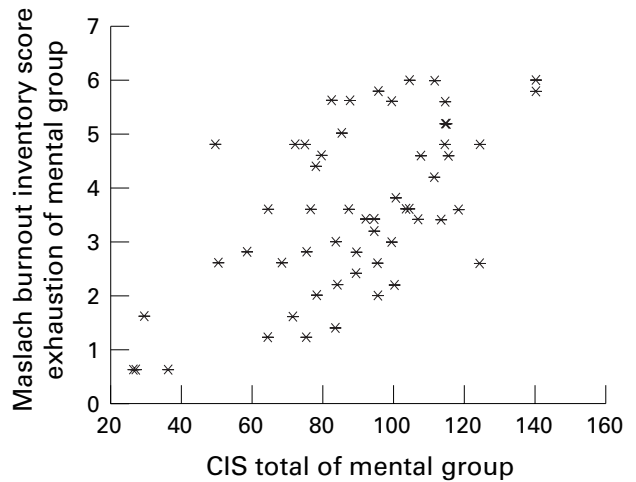

Figure 2 Scatterplot of CIS total and MBI-GS exhaustion of mental group $(n=59)$. Pearson's correlation coefficient $=0.62$.

CONVERGENT VALIDITY

Table 3 shows the results of the MBI-GS, unidimensional fatigue, and need for recovery in the five groups. Except for the scales cynicism and professional efficacy of the MBI-GS, the scores in the mental group were higher than the scores in the other groups. For the scale exhaustion of the MBI-GS and for need for recovery the differences between the mental group and all the other groups were significant. These results correspond to a large extent to the discriminant results of the CIS. Figure 2 shows the scatterplot of CIS total and the subscale exhaustion of the MBI-GS in the group of employees with a mental reason for fatigue. The corresponding correlation coefficient was 0.62 .

\section{Discussion}

The aim of this study was to evaluate the ability of the multidimensional CIS to classify study subjects according to their level of fatigue. It seemed that the CIS was able to discriminate adequately between fatigued and non-fatigued employees in occupational groups. The results of the CIS were comparable with the results of three related measures: fatigue measured on a unidimensional five point Likert scale, the scale exhaustion of the MBI-GS, and need for recovery. Also, the correlation between CIS total and the scale exhaustion of the MBI-GS in the mental group was in the expected direction and high.

No gold standard exists for fatigue. Therefore, we will never be able to prove the validity of instruments measuring fatigue. In the absence of a gold standard, direct comparisons of methods of measuring fatigue with related and existing measures are needed. In this study we compared the discriminant ability of the CIS with discriminant abilities of related measures.

It was noticeable that the group of employees with a mental reason for fatigue scored systematically higher on all dimensions of the CIS than the groups of employees with a somatic reason for fatigue. We do not know how severe the mental reason was or if these subjects also had somatic complaints. However, we noted that the scores of the patients with the chronic fatigue syndrome were substantially higher for most of the dimensions than the scores of the employees with a mental reason for fatigue.

The groups of employees with expected differences in fatigue were chosen carefully. The CIS was able to discriminate between these groups. If the CIS had not been able to discriminate between these selective groups then, we anticipated, it would certainly not be able to discriminate between less different groups.

According to Kirshner and Guyatt ${ }^{17}$ questionnaires can be used for three purposes: (a) discriminating among subjects, $(b)$ predicting prognosis, and (c) evaluating change over time. Questionnaires with different purposes require different measurement properties. ${ }^{17}$ In this study we found evidence for a satisfactory discriminating ability of the CIS. In other studies the CIS seemed to be able to measure change in fatigue scores in groups as well as in individual workers in randomised controlled trials and over a longer period..$^{9} 10$

We conclude that the CIS is able to discriminate between groups with expected differences in fatigue. The CIS seems to be an appropriate instrument for measuring fatigue in the working population.

This project was performed within the National research program on fatigue at work supported by The Netherlands Organisation for Scientific Research (NWO). We thank T van Attekum, B Bakx, M Engelen, A Köke, J Slangen, K Schröer, S Verheyen, S Wijnen, and the midwives of the Obstetric Center Maastricht for their assistance in data collection.

1 Houtman ILD, ed. Trends in arbeid en gezondheid 1996. (Trends in work and health 1996). Amsterdam: NIA/TNO, 1997.

2 Eck MAA van, De diagnosestelling "Categorie V". (The diagnose "category V"). In: Bijl R, Bauduin D, eds. Categoegory V: disabled because of mental disorders). Utrecht: NcGV, 1991.

3 Meyman T, Schaufeli WB. Psychische vermoeidheid en arbeid. (Fatigue at work). De Psycholoog 1996;june:23641 .

4 Lewis G, Wessely S. The epidemiology of fatigue: more questions than answers. If Epidemiol Community Health questions than

5 Withdrawn.

6 Smets EMA, Garssen G, Bonke B, et al. The multidimensional fatigue inventory (MFI) psychometric qualities of an instrument to assess fatigue. F Psychosom Res 1995;39:31525.

7 Vercoulen JHMM, Swanink CMA, Fennis JFM, et al. Dimensional assessment of chronic fatigue syndrome. $\mathscr{f}$ Psychosom Res 1994;38:383-92.

8 Vercoulen JHMM, Hommes OR, Swanink CMA, et al. The measurement of fatigue in patients with multiple sclerosis: a multidimensional comparison with patients with chronic fatigue syndrome and healthy subjects. Arch Neurol 1996;53:642-9.

9 Vercoulen JHMM, Swanink CMA, Fennis JFM, et al. Prognosis in chronic fatigue syndrome: a prospective study on the natural course. $\mathcal{F}$ Neurol Neurosurg Psychiatry 1996;60: 489-94.

10 Vercoulen JHMM, Swanink CMA, Zitman FG, et al. Fluoxetine in chronic fatigue syndrome: a randomized, double blind, placebo-controlled study. Lancet 1996;347:858-61.

11 Vercoulen JHMM, Alberts M, Bleijenberg G. The checklist individual strength (CIS). Gedragstherapie 1999;32:131-6.

12 Schaufeli WB, Leiter MP, Kalimo R. The general burnout inventory: a self report questionnaire to assess burnout at the workplace. In: MP Leiter, ed. Extending the burnout construct: reflecting changing career paths. Symposium, APA/NIOSH conference. Work Stress and Health 1995.

13 Veldhoven $M$ van, Meijman TF. Het meten van psychosociale arbeidsbelasting met een vragenlijst: de Vragenlijst Beleving en Beoordeling van de Arbeid (VBBA) (Questionnaire on psychosocial job demands and job stress). Amsterdam: NIA, 1994.

14 Maslach C, Jackson SE, Leiter MP. Maslach burnout inventory manual, 3rd ed. Palo Alto, CA: Consulting
Psychologists Press, 1996.

15 Leiter MP, Schaufeli WB. Consistency of the burnout construct across occupations. Anxiety Stress and Coping struct across

16 Norusis MJ. SPSS for windows. Base system user's guide release 7.0. Chicago: SPSS, 1997.

17 Kirshner B, Guyatt GH. A methodological framework for assessing health indices. F Chron Dis 1985;38:27-36. 
Appendix

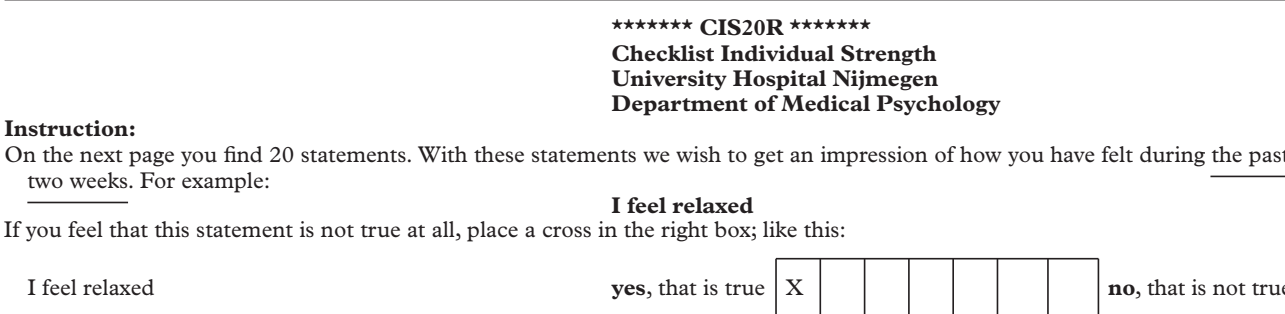

If you feel that this statement is not true at all, place a cross in the right box; like this:

I feel relaxed

yes, that is true

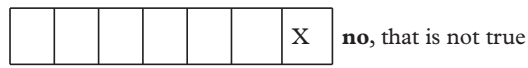

If you feel that this statement in not "yes, that is true", but also not "no, that is not true", place a cross in the box that is most in accordance with how you have felt.

For example, if you feel relaxed, but not very relaxed, place a cross in one of the boxes close to "yes, that is true": like this:

I feel relaxed

yes, that is true

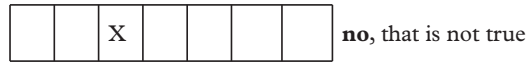

Do not skip any statement and place only one cross for each statement.

1. I feel tired

2. I feel very active

3. Thinking requires effort

4. Physically I feel exhausted

5. I feel like doing all kinds of nice things

6. I feel fit

7. I do quite a lot within a day

8. When I am doing something, I can concentrate quite well

9. I feel weak

10. I don't do much during the day

11. I can concentrate well

12. I feel rested

13. I have trouble concentrating

14. Physically I feel I am in a bad condition

15. I am full of plans

16. I get tired very quickly

17. I have a low output

18. I feel no desire to do anything

19. My thoughts easily wander

20. Physically I feel in a good shape

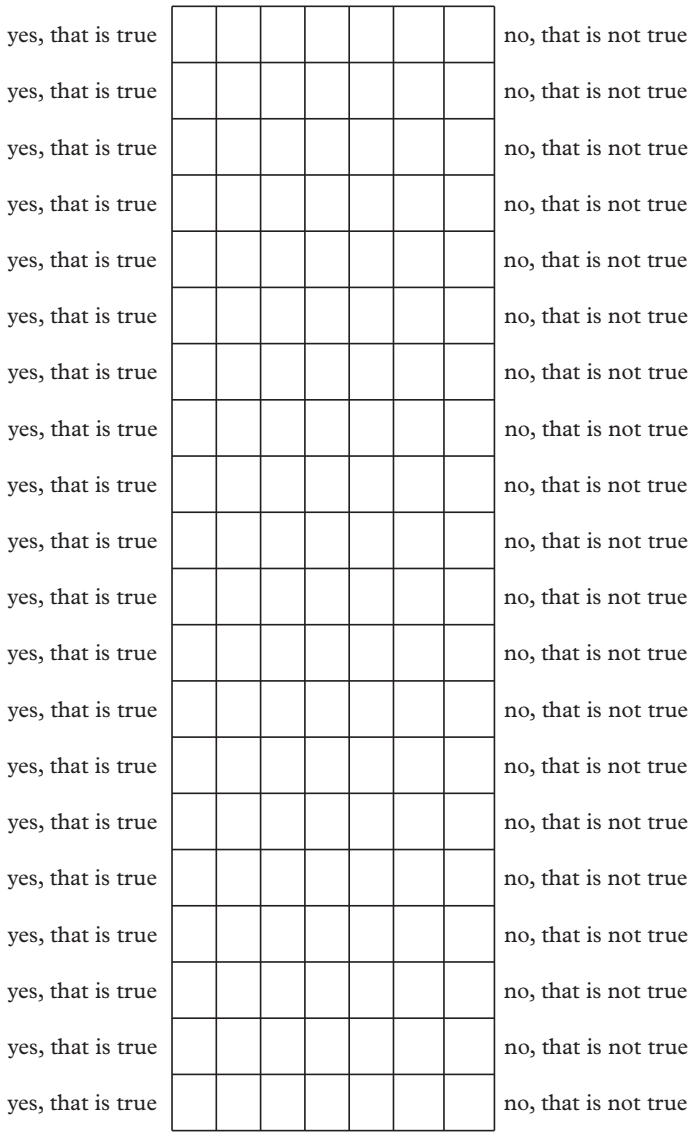

SCORING CIS20R

For the items: $\mathbf{2}, \mathbf{5}, \mathbf{6}, \mathbf{7}, \mathbf{8}, \mathbf{1 1}, \mathbf{1 2}, \mathbf{1 5}, 20$ is the scoring as follows:

yes, that is true \begin{tabular}{|l|l|l|l|l|l|l|}
\hline 1 & 2 & 3 & 4 & 5 & 6 & 7 \\
\hline
\end{tabular}

For the items: $1,3,4,9,10,13,14,16,17,18,19$ is the scoring as follows:

yes, that is true \begin{tabular}{|l|l|l|l|l|l|l|}
\hline 7 & 6 & 5 & 4 & 3 & 2 & 1 \\
\hline
\end{tabular}

Subsequently the four subscales are calculated by summing the respective items

subscale 1: Subjective feeling of fatigue items $1,4,6,9,12,14,16,20$

subscale 2: Concentration

subscale 3: Motivation

items $3,8,11,13,19$

subscale 4: Physical activity

ems $2,5,15,18$

items $7,10,17$ 